CLINICAL STUDY

\title{
Association of the Pro1 2Ala polymorphism in peroxisome proliferator-activated receptor $\gamma 2$ with decreased basic metabolic rate in women with polycystic ovary syndrome
}

\author{
Vasiliki Koika $^{1,2}$, Dimitra J Marioli ${ }^{1,2}$, Alexandros D Saltamavros ${ }^{1,2}$, Vasiliki Vervita ${ }^{1,2}$, Kleanthis D Koufogiannis ${ }^{2}$, \\ George Adonakis ${ }^{1,2}$, George Decavalas ${ }^{2}$ and Neoklis A Georgopoulos ${ }^{1,2}$ \\ ${ }^{1}$ Division of Reproductive Endocrinology and ${ }^{2}$ Department of Obstetrics and Gynecology, University of Patras Medical School, University Hospital, \\ 26500 Patras, Greece \\ (Correspondence should be addressed to N A Georgopoulos; Email: neoklisg@hol.gr)
}

\begin{abstract}
Objective: The peroxisome proliferator-activated receptor (PPAR) $\gamma$ is a transcription factor involved in glucose homeostasis and energy metabolism. A missense mutation at codon 12 in the PPAR $\gamma 2$ has been associated with increased body mass index (BMI) and attenuated insulin resistance (IR) in polycystic ovary syndrome (PCOS). We have recently shown a decreased basic metabolic rate (BMR) in PCOS. The aim of the present study is to determine the prevalence of the Pro12Ala polymorphism of the PPAR $\gamma 2$ gene and its associations with indices of IR and BMR in lean and slightly overweight PCOS women.

Design: Case-control association study involving 156 PCOS women with biochemical hyperandrogenism, chronic anovulation and polycystic ovarian morphology in ultrasound and 56 unrelated healthy controls.

Methods: Hormonal determinations were performed by electrochemiluminescence quantitation or RIA. BMR was measured by indirect calorimetry. All subjects were genotyped by a PCR-restriction fragment length polymorphism assay.

Results: Genotype frequencies of the Pro12Ala polymorphism in PPAR $\gamma 2$ did not differ among PCOS women and control subjects.The presence of Pro12Ala polymorphism of PPAR $\gamma 2$ was associated with lower BMR $(P=0.04)$. This finding was valid in our subgroup of lean PCOS $\left(\mathrm{BMI}<25 \mathrm{~kg} / \mathrm{m}^{2}\right)$, in which the Ala variant was also associated with higher total testosterone values.

Conclusion: The Pro12Ala polymorphism in the PPAR $\gamma 2$ gene is associated with decreased BMR in women with PCOS and biochemical hyperandrogenemia. These young women are therefore at risk to increase their body weight and should restrict their energy intake by diet and enhance their energy expenditure by exercise.
\end{abstract}

European Journal of Endocrinology 161 317-322

\section{Introduction}

Polycystic ovary syndrome (PCOS) is an endocrine disorder with prevalence in reproductive-aged women of $\sim 6-10 \%$ (1). PCOS can be viewed as a heterogeneous androgen excess disorder with varying degrees of hormonal and metabolic abnormalities (2). Development of PCOS may require the interaction of multiple inherited and environmental factors; therefore, PCOS appears to be a common and complex trait since the exact pattern of inheritance is yet to be fully explained.

It is well known that hyperinsulinemia and insulin resistance (IR) are common features of PCOS (3), while a substantial proportion of women with PCOS are overweight or obese. Obesity acts as an aggravating parameter of PCOS phenotype and weight loss is a usual manipulation in PCOS management. Reduction in body weight is known to restore ovulation and reduce androgen levels (3). Thus, metabolic features that make PCOS patients susceptible to gaining weight should be further investigated. Basal metabolic rate (BMR) represents the resting energy expenditure of an individual and a low BMR is considered to be a factor predisposing to obesity (4). Owing to this fact, the role of many genes involved in insulin action and secretion, energy metabolism and adipogenesis has been investigated in order to elucidate the pathogenesis of PCOS.

The nuclear receptor peroxisome proliferatoractivated receptor $(\mathrm{PPAR}) \gamma$ is a transcription factor that modulates the expression of many genes involved in glucose and lipid homeostasis and regulates the adipocyte differentiation (5). Therefore, it is a strong candidate gene predisposing to obesity via increased 
adiposity. PPAR $\gamma$ functions are mediated by two major protein isoforms produced by alternative splicing: $\operatorname{PPAR} \gamma 1$, which is widely expressed, and PPAR $\gamma 2$, which is most abundantly expressed in adipose tissue. A missense mutation in the PPAR $\gamma 2$-specific domain, yielding the alanine-to-proline substitution at codon 12 (PPAR $\gamma 2$ Pro12Ala SNP, refSNP ID: rs1801282), has been identified and related to functional consequences of PPAR $\gamma 2(6,7)$. This genotype has been associated with increased body mass index (BMI) and attenuated IR in PCOS $(8,9)$. Moreover, we have recently shown that women with PCOS, particularly those with IR, present a significantly decreased BMR (10).

The aim of the present study is to determine the prevalence of the PPAR $\gamma 2$ Pro12Ala SNP and its associations with indices of IR and BMR in a wellcharacterized cohort of lean and slightly overweight PCOS women with biochemical hyperandrogenemia.

\section{Materials and methods}

\section{Subjects}

The study included 156 Caucasian-Greek women with PCOS with a mean age of $22.46 \pm 4.41$ years and a mean BMI of $25.7 \pm 0.64 \mathrm{~kg} / \mathrm{m}^{2}$ and 56 regularly menstruating, ovulatory women with a mean age of $22.91 \pm 1.5$ years and a mean BMI of $21.191 \pm 2.5 \mathrm{~kg} / \mathrm{m}^{2}$ as controls. The diagnosis of PCOS was based on the presence of biochemical hyperandrogenism, chronic anovulation (fewer than six cycles in 12 months and serum progesterone $<5 \mathrm{ng} / \mathrm{ml}$ in 20-24 days after a spontaneous bleeding) (11), and polycystic ovarian morphology in ultrasound, thus meeting both the criteria of the 1990 National Institute of Child Health and Human Development Conference on PCOS (12) and the experts meeting in Rotterdam in 2003, sponsored by the European Society of Human Reproduction and Embryology (ESHRE) and the American Society for Reproductive Medicine (ASRM) (13). Before recruitment, PCOS women were followed up, until a spontaneous bleeding was achieved. Biochemical hyperandrogenism was defined as increased serum testosterone and/or increased free androgen index (FAI). We considered a woman having hyperandrogenemia when she had serum testosterone levels and/or FAI higher than two s.D.'s above the mean testosterone level of the controls.

Blood samples were collected between the third and fourth day of a menstrual cycle of healthy controls and on the third and fourth day after a spontaneous bleeding episode in women with PCOS, after an overnight fast. On the same day, transvaginal ultrasound examination was performed.

All controls had normal ovulating cycles with serum progesterone $>10 \mathrm{ng} / \mathrm{ml}$ in the luteal phase of the menstrual cycle (days 18-21) and no signs of clinical hyperandrogenism.

Exclusion criteria were congenital adrenal hyperplasia, androgen-secreting tumors, and Cushing's syndrome. All subjects had normal thyroid, kidney, and liver function.

All subjects gave written informed consent and the study was performed according to the guidelines of the Institutional Review Boards of the University of Patras Medical School.

\section{Methods}

Physical measurements included weight, height, fat-free mass, and fat mass. Biochemical parameters included serum testosterone, free testosterone, androstenedione, total cholesterol, triglycerides, high density lipoproteinand low density lipoprotein-cholesterol, and glucose levels. A standard oral glucose tolerance test with $75 \mathrm{~g}$ glucose was carried out. All PCOS women with type 2 diabetes or impaired glucose tolerance were excluded from the study.

FAI was calculated according to the equation: testosterone $(\mathrm{nmol} / \mathrm{l}) \times 100 / \mathrm{SHBG}(\mathrm{nmol} / \mathrm{l})$. IR was assessed by determining fasting insulin levels, fasting glucose levels, fasting glucose/insulin ratio, as well as the HOMA and QUICKI indices. Calculation of HOMA and QUICKI indices was made according to the following formulas:

HOMA-IR $=$ Fasting $\quad$ insulin $\quad(\mu \mathrm{IU} / \mathrm{ml}) \times$ Fasting glucose $(\mathrm{mmol} / \mathrm{l})(14,15)$; QUICKI $=1 / \log$ (Fasting insulin) $+\log$ (Fasting glucose) (15).

All assays for hormonal determinations were performed by electrochemiluminescence quantitation (Elecsys 2010, Roche Diagnostics) with the exception of serum androstenedione and 17-OH progesterone, which were determined by RIA using commercially available kits (BioSource, B-1400 Nivelles, Belgium).

BMR was measured by indirect calorimetry (Pulmolab EX505, Morgan Medical Ltd, Kent, UK) as previously described by Ferrannini (16) and expressed as kilocalories per day. Each subject's BMR was adjusted for fat-free mass, fat mass, sex, and age as previously described (16), using the equation: adjusted $\mathrm{BMR}=$ (group mean BMR)+(measured BMR - predicted BMR). For each subject the predicted BMR was obtained by substituting the individual lean body mass, fat mass, sex, and age in the linear regression equation generated by the data of all patients. The study complied with the principles of the Helsinki Declaration; all subjects gave their informed consent.

\section{Genotyping}

Genomic DNA was extracted from whole peripheral blood by the standard phenol/chloroform method. All DNA samples were genotyped by a PCR-restriction fragment length polymorphism as previously described (5). 
Table 1 Genotype frequencies of the Pro12Ala peroxisome proliferator-activated receptor $\gamma 2(P P A R \gamma 2)$ gene polymorphism in women with polycystic ovary syndrome (PCOS) and in the control group.

\begin{tabular}{lccc}
\hline & $\begin{array}{c}\text { PPAR } \gamma 2 \\
\text { Pro/Pro }\end{array}$ & $\begin{array}{c}\text { PPAR } \gamma \text { 2 } \\
\text { Pro/Ala }\end{array}$ & $\begin{array}{c}\text { PPAR } \gamma \text { 2 } \\
\text { Ala/Ala }\end{array}$ \\
\hline $\begin{array}{c}\text { PCOS } \\
\text { women }\end{array}$ & $n=136(87.73 \%)$ & $n=19(11.66 \%)$ & $n=1(0.61 \%)$ \\
Controls & $n=48(85.72 \%)$ & $n=6(10.71 \%)$ & $n=2(3.57 \%)$ \\
\hline
\end{tabular}

\section{Statistical analysis}

The genotype frequency distributions were tested for Hardy-Weinberg equilibrium and compared with the genotype frequencies of a group of normal subjects by $\chi^{2}$ test. The independent sample t-test, with twotailed test of statistical significance, and the Levene's test for equality of variances were used to assess the statistical significance of the difference of the means between variables that were found to be normally distributed according to Kolmogorov-Smirnov test. Values that were normally distributed were BMR, androstenedione, QUICKI, and free testosterone. For all other non-Gaussian variables such as HOMA-IR, fasting insulin, testosterone, fasting glucose/fasting insulin ratio, age, BMI, 17-OH Prog, and FAI we used the Mann-Whitney test. A critical value of $P<0.05$ was considered to be significant. All statistical procedures were performed using SPSS 11.0 for Windows (SPSS Inc., Chicago, IL, USA).

\section{Results}

Genotype frequencies of the Pro12Ala in the nuclear receptor PPAR $\gamma 2$ are presented in Table 1. Genotype frequencies were compared between PCOS women and a group of regularly menstruating, ovulatory women used as control group. No association of the polymorphisms with PCOS phenotype was detected. Within PCOS women, the presence of the polymorphism was related to the clinical and biochemical features of the PCOS phenotype that are presented in Table 2. All statistical procedures related to PPAR $\gamma 2$ polymorphism were performed between the Pro/Pro and Pro/Ala plus the Ala/Ala subgroups (X/Ala), as the Ala/Ala group was too small to provide statistical power.

The presence of Pro12Ala polymorphism of PPAR $\gamma 2$ was associated with BMR, since the Ala allele carriers had lower BMR compared with the Pro/Pro women $(1475.7 \pm 678.6$ vs $893.2 \pm 312.3 \mathrm{kcal} / \mathrm{day}, P=0.04$; Table 2; Fig. 1).

Subsequently, in order to further evaluate the relationship of the Pro12Ala polymorphism of PPAR $\gamma 2$ with IR, we divided all PCOS women according to IR indices into two subgroups: those with IR $(n=39$; fast insulin $>12 \mathrm{mU} / \mathrm{ml}$, Glu/Ins $<6.4$, HOMA $>2.16$, QUICKI $<0.333)$ and those without IR $(n=77$; fast insulin $<12 \mathrm{mU} / \mathrm{ml}$, Glu/Ins $>6.4$, HOMA $<2.16$, QUICKI $>0.333)$. Forty out of 156 PCOS women did not fit all the applied criteria for IR and therefore were not included in these two subgroups. Among PCOS women with and without IR, concerning the gene polymorphism studied, no statistically significant differences were detected between groups with the normal or the polymorphic allele in all investigated clinical and biochemical features $(P=\mathrm{NS})$.

However, when PCOS women were further divided into two groups according to BMI, PCOS women with $\quad \mathrm{BMI}<25 \mathrm{~kg} / \mathrm{m}^{2} \quad\left(\mathrm{BMI}=21.08 \pm 2.15 \mathrm{~kg} / \mathrm{m}^{2}\right)$ carrying the Pro12Ala polymorphism had a BMR significantly lower than those without the polymorphic change $(\mathrm{BMR}=1481 \pm 594$ vs $716 \pm 222 \mathrm{kcal} / \mathrm{day}$

Table 2 Clinical characteristics in polycystic ovary syndrome women according to different peroxisome proliferator-activated receptor $\gamma 2$ variants. Values are mean \pm s.D. range.

\begin{tabular}{|c|c|c|c|c|}
\hline & Total $n=156$ & Pro/Pro $n=136$ & X/Ala $n=20$ & $P$ value \\
\hline Age (years) & $22.82 \pm 4.99(15-42)$ & $22.81 \pm 5.17(15-42)$ & $22.92 \pm 3.12(18-30)$ & 0.54 \\
\hline Body mass index $\left(\mathrm{kg} / \mathrm{m}^{2}\right)$ & $25.62 \pm 6.44(17.10-47.3)$ & $25.76 \pm 6.69(17.10-47.30)$ & $24.40 \pm 3.49(19-29.70)$ & 0.94 \\
\hline Fasting insulin $(\mu \mathrm{IU} / \mathrm{ml})$ & $9.88 \pm 5.88(1.0-37.0)$ & $9.97 \pm 6.05(1.0-37.0)$ & $9.12 \pm 4.42(3.19-19.90)$ & 0.81 \\
\hline Fasting glucose/insulin & $11.85+12.06(0.78-86)$ & $11.98+12.59(0.78-86.00)$ & $10.75+5.94(4.37-25.39)$ & 0.73 \\
\hline HOMA-IR & $2.32 \pm 2.45(0.15-18.26)$ & $2.35 \pm 2.56(0.15-18.6)$ & $2.08 \pm 1.19(0.94-5.08)$ & 0.66 \\
\hline QUICKI & $0.357+0.044(0.257-0.525)$ & $0.357+0.05(0.257-0.525)$ & $0.358+0.028(0.308-0.414)$ & 0.97 \\
\hline Testosterone $(\mathrm{ng} / \mathrm{ml})$ & $0.77 \pm 0.04(0.15-2.30)$ & $0.77 \pm 0.40(0.15-2.30)$ & $0.80 \pm 0.386(0.30-1.60)$ & 0.67 \\
\hline Free testosterone $(\mathrm{pg} / \mathrm{ml})$ & $2.99+1.77(0.61-14.0)$ & $2.97+0.18(0.61-14)$ & $3.11+1.30(1.60-5.60)$ & 0.79 \\
\hline $17-\mathrm{OH}$ Prog $(\mathrm{ng} / \mathrm{ml})$ & $1.23 \pm 0.75(0.34-5.50)$ & $1.24 \pm 0.78(0.34-5.50)$ & $1.09 \pm 0.47(0.50-2.10)$ & 0.70 \\
\hline Androstenedione $(\mathrm{ng} / \mathrm{ml})$ & $3.31+1.33(1.20-8.00)$ & $3.30+1.32(1.25-8)$ & $3.40+1.48(1.20-6.00)$ & 0.79 \\
\hline Free androgen index & $0.70+1.43(0.04-15.07)$ & $0.73+0.15(0.04-15.07)$ & $0.47+0.39(0.06-1.06)$ & 0.56 \\
\hline $\begin{array}{l}\text { Basic metabolic rate } \\
\text { (kcal/day) }\end{array}$ & $1415.7 \pm 672.9(328.2-3969)$ & $1475.7 \pm 678.6(328.2-3969.0)$ & $893.2 \pm 312.4(532.2-1299.7)$ & 0.04 \\
\hline Cholesterol (mg/dl) & $192.80 \pm 46.78(111-384)$ & $193.32 \pm 47.21(114-384)$ & $188.33 \pm 44.54(111-252)$ & 0.87 \\
\hline Triglycerides (mg/dl) & $92.28+48.86(27-295)$ & $94.49+49.74(27-295)$ & $73.75+37.32(31-144)$ & 0.15 \\
\hline $\mathrm{HDL}-\mathrm{C}(\mathrm{mg} / \mathrm{dl})$ & $56.74 \pm 13.76(26-109)$ & $55.57 \pm 12.21(26-92)$ & $66.58 \pm 21.36(39-109)$ & 0.10 \\
\hline LDL-C (mg/dl) & $116.91 \pm 41.15(54-301)$ & $118.07 \pm 41.51(63.8-301)$ & $107.28 \pm 38.29(54-174)$ & 0.54 \\
\hline
\end{tabular}

$P$ values between Pro/Pro and X/Ala variants. 


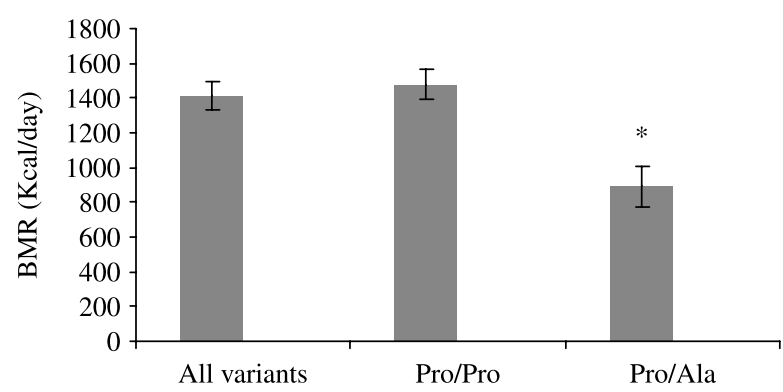

Figure 1 Basic metabolism rate (BMR) in women with PCOS according to the presence of the Pro12Ala PPAR $\gamma 2$ genotype. Values are mean \pm S.E.M. ${ }^{*} P<0.05$.

respectively, $P=0.035)$. In these lean PCOS women, the Pro12Ala polymorphism of PPAR $\gamma 2$ was also associated with higher total testosterone values but not with indices of IR. On the contrary, in PCOS women with $\mathrm{BMI}>25 \mathrm{~kg} / \mathrm{m}^{2} \quad\left(\mathrm{BMI}=31.18 \pm 4.54 \mathrm{~kg} / \mathrm{m}^{2}\right) \quad$ the association of the Ala variant was not replicated either with BMR or with total testosterone values.

\section{Discussion}

In the present study, we addressed the question whether PPAR $\gamma 2$ Pro12Ala SNP is related to PCOS phenotype and quantitative traits of the syndrome such as obesity, IR, and BMR in a distinct phenotypic group of Caucasian young PCOS patients characterized by biochemical hyperandrogenemia, chronic anovulation, and polycystic ovaries in ultrasound. Our PCOS women met both the diagnostic criteria of the $1990 \mathrm{NIH}$ conference (12) and the revised consensus criteria of Rotterdam ESHRE/ASRM 2003 (13). Hence, bearing the form of the most severe PCOS with hyperandrogenemia and chronic anovulation (17), a suitable population for genotypic analysis.

In order to detect causative genetic variants for PCOS, confounding aggravating parameters of the syndrome's phenotypic feature such as obesity should be excluded from the study cohort. Therefore, ideally, lean and obese PCOS women should be studied separately (3) and compared with the BMI-matched general population. However, there are few studies in literature in which lean PCOS women have been separately studied (3) and no genetic association study, evaluating the effect of PPAR $\gamma 2$ and BMR in lean PCOS women, has been reported to date.

We showed that, in women with PCOS, the presence of Pro12Ala polymorphism in the PPAR $\gamma 2$ gene was associated with lower BMR. To our knowledge, this is the first study to demonstrate an association of the PPAR $\gamma 2$ Pro12Ala SNP with lower BMR in PCOS.

The association of the Pro12Ala polymorphism with BMR was investigated only once in a cohort of very obese women but never in women with PCOS (8). In this study by Valve et al., no association of the Pro12Ala polymorphism with BMR was detected. It should be noted that PCOS women included in our study were normal weight or slightly overweight. This discrepancy might be due to the presence of elevated expression of PPAR $\gamma$ by excessive fat mass that inhibits the suppression of insulin-induced lipolysis through transcriptional alterations due to the Pro12Ala polymorphism. Therefore, the influence of the PPAR $\gamma 2$ Pro12Ala SNP on BMR might be different among lean or obese subjects. Nevertheless, low BMR does not necessarily mean high BMI, as BMR values in obesity are reported within normal (18) or increased ranges (19), while we have recently shown decreased BMR in normal weight PCOS women (10). Nevertheless, the association of the Pro12Ala polymorphism with BMR was valid and in our subgroup of lean PCOS with BMI $<25 \mathrm{~kg} / \mathrm{m}^{2}$, excluding the confounding effect of obesity.

Thanks to the dual role of PPAR $\gamma$ in adipogenic regulation and in modulation of intracellular insulinsignaling events, this molecule is in a prominent position in the list of various candidate genes involved in multi-genetic traits such as type 2 diabetes mellitus and PCOS (17). Concerning Pro12Ala allelic frequencies, our findings are in agreement with the majority of studies that did not detect any difference between PCOS women and the general population $(9,20-28)$. On the contrary, in a Finnish population of PCOS women (29), the frequency of Ala allele was found to be reduced with a slight significance, suggesting a protective role against the development of the syndrome. Despite this general agreement concerning allelic frequencies, several studies reported different associations of the Pro12Ala polymorphism in the $P P A R \gamma 2$ gene with several phenotypic traits of hyperandrogenism and IR in PCOS women. Hara et al. (9) in a multi-ethnic study of obese PCOS women, reported that the Ala allele carriers were more insulin sensitive and presented a tendency to lower total and free testosterone levels. Hahn et al. (26) reported lower hyperinsulinaemia and all parameters of IR in obese but not in lean PCOS subjects carrying the Ala allele. Tok et al. (30) reported that lean women with PPAR $\gamma 2$ Pro12Ala SNP had significant higher BMI, while, on the contrary, Yilmaz et al., in a population of similar ethnic origin lean PCOS women reported an association of the Pro12Ala with lower BMI and lower waist-to-hip ratio, reduced androgen levels, less hirsutism, and lower IR index (31).

Although concerning BMI, a statistically significant difference was noted between PCOS women and the control group $(P<0.001)$, still in our studied cohort no association between BMI and the presence of the Ala allele was detected in either PCOS women or in the control group. Nevertheless, after dividing our PCOS women according to BMI, PCOS women with $\mathrm{BMI}<25 \mathrm{~kg} / \mathrm{m}^{2} \quad\left(\mathrm{BMI}=21.08 \pm 2.15 \mathrm{~kg} / \mathrm{m}^{2}\right)$ did not present any statistically significant difference in allelic frequencies with the matched for BMI control group. 
In our study, we did not detect any association of the PPAR $\gamma 2$ Pro12Ala SNP with either BMI or glucose homeostasis. Nevertheless, the PPAR $\gamma 2$ 12Ala allele was associated with higher testosterone levels in PCOS women of normal weight $\left(\mathrm{BMI}<25 \mathrm{~kg} / \mathrm{m}^{2}\right)$. These results are apparently contradictory with the findings of Hara et al. (9) and Yilmaz et al. (31) but it should be noted that these two studies refer to obese PCOS women. It is well known that testosterone induces lipolysis and therefore it is reasonable to find an association of the Ala variant with higher testosterone levels in these lean women with PCOS and biochemical hyperandrogenemia.

Furthermore, association studies of the Pro12Ala polymorphism in populations of different BMI demonstrated conflicting results. Among normal weight or slightly overweight subjects, the Ala12 variant was associated with lower than average BMI (7). Beamer et al. in two independent Caucasian populations found that the Pro12Ala was associated with higher BMI in subjects with morbid obesity, while in lean-to-moderately obese subjects a tendency towards a higher BMI was reported, which did not reach statistical significance (32). Furthermore, Valve et al. reported an association of PPAR $\gamma 2$ Pro12Ala SNP with severe overweight and increased fat mass among obese women (8). These results suggest that genetic variation at the PPAR $\gamma$-locus may influence susceptibility to obesity in humans in different ways.

The Ala allele has been shown to present lower affinity and transactivation capacity than the pro-allele in pre-adipocyte cell lines, while both insulin sensitivity of glucose disposal and lipolysis were greater in the subjects carrying the Ala allele (33). Indeed, in our study a tendency, that did not reach statistical significance probably due to small number of Ala carriers detected, was noted for lower fasting insulin levels in subjects carrying the Ala allele. Given the fact that the messenger ribonucleic acid expression of PPAR $\gamma 2$ is increased in adipose tissue of obese subjects, and is down-regulated by a low calorie diet, the functional significance of the Pro12Ala substitution may be dependent on energy reserves, different among normal weight, obese or morbidly obese subjects (33). This observation could, at least partly, explain the contradictory associations of the Ala allele in different populations.

The finding that the presence of the Ala allele in adipocytes, through altered transcription activity of the receptor, enhances the suppressing insulin action on lipolysis, indicates a shift of the lipolysis-lipogenesis balance towards lipogenesis. Insulin-sensitive subjects are more likely to gain weight than insulin-resistant ones (34). Therefore, the subjects carrying the Ala allele in our cohort are prone to gain weight.

A major concern in our study is that in the control group used for allelic frequencies determinations no assessment of BMR was performed. Therefore, further studies are needed to determine the influence of the PPAR $\gamma 2$ Pro12Ala SNP on BMR in distinct populations of lean, overweight, and obese regularly menstruating, ovulatory women as well as in overweight and obese women with PCOS.

In conclusion, the results of this study demonstrates that the PPAR $\gamma 2$ Pro12Ala SNP is associated with decreased BMR in women with PCOS and biochemical hyperandrogenemia when compared with Pro/ProPCOS women, still, an eventual similar association in regularly menstruating women cannot be excluded. Therefore, these young women are at risk to increase their body weight and should restrict their energy intake by diet and enhance their energy expenditure by exercise.

\section{Declaration of interest}

There is no conflict of interest that could be perceived as prejudicing the impartiality of the research reported.

\section{Funding}

This study did not receive any specific grant from any funding agency in the public, commercial or not-for-profit sector.

\section{References}

1 Azziz R, Woods KS, Reyna R, Key TJ, Knochenhauer ES \& Yildiz BO. The prevalence and features of the polycystic ovarian syndrome in an unselected population. Journal of Clinical Endocrinology and Metabolism 200498 2745-2749.

2 Carmina E \& Lobo RA. Polycystic ovary syndrome (PCOS): arguably the most common endocrinopathy is associated with significant morbidity in women. Journal of Clinical Endocrinology and Metabolism $1999 \mathbf{8 4} 1897-1899$.

3 Dunaif A. Insulin resistance and the polycystic ovary syndrome: mechanism and implications for pathogenesis. Endocrine Reviews $199718774-800$.

4 Ravussin E, Lillioja S, Knowler WC, Christin L, Freymond D, Abbott WG, Boyce V, Howard BV \& Bogardus C. Reduced rate of energy expenditure as a risk factor for body-weight gain. New England Journal of Medicine 1988318 467-472.

5 Auwerx J. PPARgamma, the ultimate thrifty gene. Diabetologia 199942 1033-1049.

6 Yen CJ, Beamer BA, Negri C, Silver K, Brown KA, Yarnall DP, Burns DK, Roth J \& Shuldiner AR. Molecular scanning of the human peroxisome proliferator activated receptor gamma (hPPAR gamma) gene in diabetic Caucasians: identification of a Pro12Ala PPAR gamma 2 missense mutation. Biochemical and Biophysical Research Communications 1997241 270-274.

7 Deeb SS, Fajas L, Nemoto M, Pihlajamaki J, Mykkanen L, Kuusisto J, Laakso M, Fujimoto W \& Auwerx J. A Pro12Ala substitution in PPARgamma2 associated with decreased receptor activity, lower body mass index and improved insulin sensitivity. Nature Genetics $199820284-287$.

8 Valve R, Sivenius K, Miettinen R, Pihlajamäki J, Rissanen A, Deeb SS, Auwerx J, Uusitura M \& Laakso M. Two polymorphisms in the peroxisome proliferator-activated receptor-gamma gene are associated with severe overweight among obese women. Journal of Clinical Endocrinology and Metabolism $1999843708-3712$.

9 Hara M, Alcoser SY, Qaadir A, Beiswenger KK, Cox NJ \& Ehrmann DA. Insulin resistance is attenuated in women with 
polycystic ovary syndrome with the Pro(12)Ala polymorphism in the PPARgamma gene. Journal of Clinical Endocrinology and Metabolism 200287 772-775.

10 Georgopoulos NA, Saltamavros AD, Vervita V, Karkoulias K, Adonakis G, Decavalas G, Kourounis G, Markou KB \& Kyriazopoulou V. Basal metabolic rate is decreased in women with polycystic ovary syndrome and biochemical hyperandrogenemia and is associated with insulin resistance. Fertility and Sterility, 2008. In press. DOI: 10.1016/j.fertnstert.2008. 04.067

11 Azziz R, Nestler JE \& Dewailly D. Androgen Excess Disorders in Women: Polycystic Ovary Syndrome and Other Disorder, ch 13, pp 146-147. Totowa, NJ, USA: Humana Press 2006.

12 Zawadski JK \& Dunaif A. Diagnostic criteria for polycystic ovary syndrome. In Polycystic Ovary Syndrome, pp 377-384. Eds A Dunaif, JR Givens, FP Haseltine \& GE Merriam, Boston, MA, USA: Blackwell Scientific, 1992.

13 The Rotterdam ESHRE/ASRM-Sponsored PCOS Consensus Workshop Group 2004. Revised 2003 consensus on the diagnostic criteria and long term health risks related to polycystic ovary syndrome. Fertility and Sterility 200381 19-25.

14 Panidis D, Macut D, Farmakiotis D, Rousso D, Kourtis A, Katsikis I, Spanos N, Petakov M, Bjekic J \& Damjanovic S. Indices of insulin sensitivity, beta cell function and serum proinsulin levels in the polycystic ovary syndrome. European Journal of Obstetrics, Gynecology, and Reproductive Biology 2006127 99-105.

15 Matsuda M \& DeFronzo RA. Insulin sensitivity indices obtained from oral glucose tolerance testing: comparison with the euglycemic insulin clamp. Diabetes Care 199922 1462-1470.

16 Ferrannini E. The theoretical basis of indirect calorimetry: a review. Metabolism 198837 287-301.

17 Norman RJ, Dewailly D, Legro RS \& Hickey TE. Polycystic ovary syndrome. Lancet 2007 370 685-697.

18 Halliday D, Hesp R, Stalley SF, Warwick P, Altman DG \& Garrow JS. Resting metabolic rate, weight, surface area and body composition in obese women. International Journal of Obesity 19793 1-6.

19 James WPT, Davies HL, Bailes J \& Dauncey MJ. Elevated metabolic rates in obesity. Lancet $1978 \mathbf{1} 1122-1125$.

20 Mierhaeghe A \& Amouyel P. Impact of genetic variation of PPAR $\gamma$ in humans. Molecular Genetics and Metabolism 200483 93-102.

21 Urbanek M, Legro RS, Driscoll DA, Azziz R, Ehrmann DA, Norman RJ, Strauss JF, Spielman RS \& Dunaif A. Thirty-seven candidate genes for polycystic ovary syndrome: strongest evidence for linkage is with follistatin. PNAS 199996 8573-8578.

22 Ehrmann DA, Tang X, Yoshiuchi I, Cox NJ \& Bell GI. Relationship of insulin receptor substrate-1 and -2 genotypes to phenotypic features of polycystic ovary syndrome. Journal of Clinical Endocrinology and Metabolism 200287 4297-4300.

23 El Mkadem SA, Lautier C, Macari F, Molinari N, Lefèbvre P, Renard E, Gris JC, Cros G, Daurès JP, Bringer J, White MF \& Grigorescu F. Role of allelic variants Gly972Arg of IRS-1 and Gly1057Asp of IRS-2 in moderate-to-severe insulin resistance of women with polycystic ovary syndrome. Diabetes $2001 \mathbf{5 0}$ 2164-2168.

24 Sir-Petermann T, Angel B, Maliqueo M, Santos JL, Riesco MV, Toloza H \& Pérez-Bravo F. Insulin secretion in women who have polycystic ovary syndrome and carry the Gly972Arg variant of insulin receptor substrate-1 in response to a high-glycemic or low-glycemic carbohydrate load. Nutrition 200420 905-910.
25 Villuendas G, Botella-Carretero JI, Roldán B, Sancho J, Escobar-Morreale HF \& San Millán JS. Polymorphisms in the insulin receptor substrate-1 (IRS-1) gene and the insulin receptor substrate-2 (IRS-2) gene influence glucose homeostasis and body mass index in women with polycystic ovary syndrome and non-hyperandrogenic controls. Human Reproduction 200520 3184-3191.

26 Hahn S, Fingerhut A, Khomtsiv U, Khomtsiv L, Tan S, Quadbeck B, Herrmann BL, Knebel B, Müller-Wieland D, Mann K \& Janssen OE. The peroxisome proliferator-activated receptor gamma Pro12Ala polymorphism is associated with lower hirsutism score and increased insulin sensitivity in women with polycystic ovary syndrome. Clinical Endocrinology 200562 573-579.

27 Orio F, Palomba S, Cascella T, Di Biase S, Labella D, Russo T, Savastano S, Zullo F, Colo A, Vettor R \& Lombardi G. Lack of association between peroxisome proliferator-activated receptor- $\gamma$ gene Pro12Ala polymorphism and adiponectin levels in the polycystic ovary syndrome. Journal of Clinical Endocrinology and Metabolism 200489 5110-5115.

28 San Millan JL, Corton M, Villuendas G, Sancho J, Peral B \& Escobar-Morreale HF. Association of the polycystic syndrome with genomic variants related to insulin resistance, type 2 diabetes mellitus and obesity. Journal of Clinical Endocrinology and Metabolism 200489 2640-2646.

29 Korhonen S, Heinonen S, Hiltunen M, Helisalmi S, Hippelainen M, Koivunen R, Tapanainen JS \& Laakso M. Polymorphism in the peroxisome proliferator-activated receptor- $\gamma$ gene in women with polycystic ovary syndrome. Human Reproduction 200318 540-543.

30 Tok EC, Aktas A, Ertunc D, Erdal EM \& Dilek S. Evaluation of glucose metabolism and reproductive hormones in polycystic ovary syndrome on the basis of peroxisome proliferator-activated receptor (PPAR) $\gamma 2$ Pro12Ala genotype. Human Reproduction 200520 1590-1595.

31 Yilmaz M, Ali Ergun M, Karakoc A, Yurtcu E, Cakir N \& Arslan M. Pro12Ala polymorphism of the peroxisome proliferator-activated receptor- $\gamma$ gene in women with polycystic ovary syndrome. Gynecological Endocrinology 200622 336-342.

32 Beamer BA, Yen CJ, Andersen RE, Muller D, Dariush E, Cheskin LJ, Andres R, Roth J \& Shuldiner AR. Association of the Pro12Ala variant in the peroxisome proliferator-activated receptor-2 gene with obesity in two Caucasian populations. Diabetes 199847 1806-1808.

33 Stumvoll M, Wahl HG, Loblein K, Becker R, Machicao F, Jacob S \& Haring H. Pro12Ala polymorphism in the peroxisome proliferatoractivated receptor-g2 gene is associated with increased antilipolytic insulin sensitivity. Diabetes 200150 876-881.

34 Vidal-Puig AJ, Considine RV, Jimenez-Liñan M, Werman A, Pories WJ, Caro JF \& Flier JS. Peroxisome proliferator-activated receptor gene expression in human tissues: effects of obesity, weight loss, and regulation by insulin and glucocorticoids. Journal of Clinical Investigation 199799 2416-2422.

Received 16 April 2009

Accepted 20 May 2009 